\title{
O INCIPIT DE CIDADE DE DEUS ${ }^{I}$
}

\section{César Takemoto*}

\section{Resumo}

O artigo é composto de uma breve análise das múltiplas aberturas de páginas do primeiro romance de Paulo Lins. A partir daquilo que em Teoria Literária alguns chamam de incipit, fez-se um comentário da multiplicidade de 'começos' que singularizam a narrativa em questão, levando em conta, num primeiro plano, aquilo que ela representa como radical indecisão da forma literária que dali se desenrolará. Em um segundo plano, o texto tenta desenvolver alguns temas que surgem nessas passagens iniciais, temas que serão desenvolvidos posteriormente no romance como um todo.

\section{Palavras-chave}

incipit, análise literária, indecisão formal, temas da narrativa.

\begin{abstract}
The article comprises a brief analysis of the multiple openings of Paulo Lins' first novel. Starting from what some in Literary Theory call incipit, a commentary of the multiplicity of openings that singularizes the narrative in question is made, taking into account, in a first moment, what this very multiplicity represents as radical indecision of the literary form that is going to be systematized in its further development. In a second moment, the text tries to develop some of the themes that emerge in these initial passages, themes that are also to be developed throughout the entire novel.
\end{abstract}

\section{Keywords}

incipit, literary analysis, formal indecision, narrative's themes.

* Mestre em Teoria Literária e Literatura Comparada pela FFLCH - USP. E-mail: cesartakem@hotmail.com.

1 Trabalho aqui com a primeira edição do romance, de 1997, substancialmente maior, e menos 'editada', do que as posteriores. 
Em 7/04/2009, às 18:29:09, Joel Almeida disse:

Foi essa enchente que 'desmontou' inúmeras favelas na cidade. Foi a mão de Deus... Não deveriam deixar que se reerguessem. Agora, aguentem... ${ }^{2}$

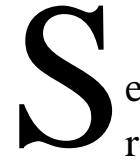

e acaso decidíssemos lançar um primeiro olhar analítico sobre o romance de Paulo Lins e, para esse olhar, considerássemos algumas questões postas pelo que se convencionou chamar de incipit romanesco (DEL LUNGO, 2003; MICHEL, 1998), teríamos quase forçosamente que constatar que a questão do 'como começar' está posta ali como indecisão. Foi Roberto Schwarz quem primeiro tomou nota dessa característica, por assim dizer inaugural, desse catatau de prosa (SCHWARZ, 1999, p. 164), “certa oscilação para começar” (PACHECO, 2007, pp. 27-45) que se formaliza em três aberturas de página no início da primeira parte do romance, A história de Cabeleira.

Mas, a tomar esta noção a sério, o verdadeiro incipit do romance estaria lá pela página 24 (LINS, 1997), quando Cabeleira aparece com Marreco e Alicate para a primeira cena de ação do livro, cena que encarna o tom predominante do romance, com suas rapidíssimas evocações de lugares através de flashes de ações sequenciais: "Marreco, Cabeleira e Alicate passaram correndo pelo Lazer, entraram na praça da Loura, saíram em frente ao bar do Pinguim, onde estava parado o caminhão de gás". A simplicidade da organização sintática, sua redução ao mínimo, autoriza essa agilidade extraordinária do movimento, que vai dos agentes da ação a seu objeto/alvo como que deslizando pelos verbos. Estes, por seu pragmatismo semântico e passado simples, alavancam a ação como roldanas, ao invés de emperrá-la. Notemos que por todo o fragmento em questão, o elemento 'descrição' é nulo. A ação é absoluta. Quem são Marreco, Cabeleira e Alicate? Não sabemos, mas sabemos ou rapidamente ficamos sabendo o que eles fizeram. O que vem em seguida é a ordem de Marreco, em discurso direto ("Todo mundo quetinho, senão leva tiro!"), que para impor seu recado se vale de um revólver em cada mão. É um eco do "Falha a fala. Fala a bala", posto na página anterior como uma possibilidade sempre presente nesse universo. A fala não falha e a bala não chega a falar, mas é exatamente a possibilidade de sua ação, sua iminência potencial, que garante poder performático à sua fala. Em outras palavras, é a capacidade de fala da arma que garante que o recado de Marreco seja passado, que o que ele quer se cumpra. Se de fato esse assalto é o momento de abertura, momento inicial a partir do qual a narrativa se engrena, "adquire o andamento que fascinará o leitor até o final" (SCHWARZ, 1999, p. 164), qual será a sua relação com os três trechos que lhe

2 Comentário feito no site <http://fotolog.terra.com.br/sdorio:91> (sem indicação autoral) que, a partir de uma imagem da grande enchente do Rio de 1966, evoca lembranças e provoca inúmeros outros comentários e histórias sobre a ocasião. 
precedem, e em particular com o da invocação propriamente dita? A invocação da Poesia, no trecho isoladamente mais próximo do gênero poético, seria parte essencial do incipit narrativo? Creio haver aqui elementos importantes para se pensar algo da poética dessa prosa, sua poesia particular. Transcrevamo-no:

Poesia, minha tia, ilumine as certezas dos homens e os tons de minhas palavras. É que arrisco a prosa mesmo com balas atravessando os fonemas. É o verbo, aquele que é maior que o seu tamanho, que diz, faz e acontece. Aqui ele cambaleia baleado. Dito por bocas sem dentes e olhares cariados, nos conchavos dos becos, nas decisões de morte. A areia move-se nos fundos dos mares. A ausência de sol escurece mesmo as matas. O líquido-morango do sorvete mela as mãos. A palavra nasce no pensamento, desprende-se dos lábios adquirindo alma nos ouvidos, e às vezes essa magia sonora não salta à boca porque é engolida a seco. Massacrada no estômago com arroz e feijão a quase palavra é defecada ao invés de falada.

Falha a fala. Fala a bala. (LINS, 1997, p. 23)

Muitos observaram que o trecho é uma invocação (à moda) épica. E poderíamos mesmo num primeiro momento relacionar tal invocação épica a certa tendência do romance de se aproximar das formas épicas, na medida em que a obra, mesmo que se centre em determinadas figuras individuais, dá a ver um destino propriamente coletivo. Olhando mais de perto, porém, percebemos que a invocação não é feita à musa da poesia, mas diretamente à poesia, cuja feição é tanto familiar como coloquial - parte da semântica da palavra 'tia'. A escrita é de prosa, mas é através de uma poética coloquial - da proximidade, se quisermos - que se deve atingir a clareza prática necessária tanto para a compreensão das ações humanas, quanto do modo de narrá-las. A motivação é iluminista, mas o tom é de prece. A poesia, ou o lirismo, é invocada para que a prosa consiga se impor sem que estejam asseguradas as condições para que ela o faça. A linguagem dilacerada ou danificada - temas da estética do século $\mathrm{XX}$ - procura na poesia coloquial uma forma de contornar sua precariedade. O que parece estar em jogo aqui não é simplesmente o verbo codificado no texto, inscrito no mundo simbólico-ficcional, mas o verbo "que é maior que o seu tamanho, que diz, faz e acontece", o verbo em sua dimensão performativa (DUBOIS, 2004, p. 464). É o verbo de Marreco ordenando: “Todo mundo quetinho, senão leva tiro!". Verbo cuja força pode acabar de forma tão súbita quanto se impôs, que mesmo em sua potência revela a sua precariedade. Verbo cujos sujeitos são reduzidos aos seus traços mais flagrantemente precários: "Dito por bocas sem dentes e olhares cariados". Estão condensados aqui os traços dos heróis desse romance, numa gama que vai da criança ainda sem dentição permanente ao eterno banguela da pobreza absoluta, complementados pelos seus momentos-chave, "nos conchavos de becos, nas decisões de morte", ou seja, os da sociabilidade do ressentimento e da "luta de morte" (PASTA JR., 1999, pp. 61-70).

Em seguida, temos duas imagens montadas com elementos da natureza comuns mesmo à natureza carioca (areia, mar, sol, matas) -, imagens que são as mais enigmáticas do trecho, cenas cuja escuridão pode sugerir certo obscurantismo. $\mathrm{O}$ fundo dos mares é o insondável, a grande escuridão que, no entanto, é repleta de uma vida e um movimento diferentes dos das praias, estas cuja beleza banalizada se dá a ver a 
nossa incansável contemplação. As matas, escuras por natureza, podem tornar-se ainda mais sombrias na falta de sol. Mas o que são essas áreas negras, repletas de vida invisível? Seriam a figuração do espaço da narrativa, ao mesmo tempo oposto à praia e próximo das matas, da natureza, mergulhado num obscurantismo que não vê limite, mas que é tanto nosso quanto próprio? Vencer o obscurantismo do leitor, conseguir tecer uma prosa que consiga desprender-se "dos lábios" e adquirir "alma nos ouvidos" traduz então o desafio que o próprio narrador se lança.

Mas há ainda outro desafio que - acredito - também deve ser levado em conta para que o obscurantismo, a ignorância que temos do mundo em questão - que se não é exatamente o nosso, também o é, porque nos diz respeito - sejam vencidos. E creio estar esse desafio cifrado na oração "O líquido-morango do sorvete mela as mãos". À primeira vista, nada mais descabido do que este trecho. Há algo de infantil nele, pela imagem que sugere, mas a constatação é séria e adulta. A artificialidade da construção "líquido-morango" identifica-se com a artificialidade da guloseima, e há algo de uma impregnação sinestésica nisso: a aliteração do $m$ sugere o melado do tato. A sugestão no seu todo não é agradável, mas não chega a causar asco. Se imaginarmos tratar-se das mãos de uma criança, entretanto não se pode estar seguro de que ela esteja incomodada, aliás, é provável que seja mesmo o contrário disso. O que parece se impor, entretanto, é algo que pode soar como de mau gosto, da ordem do poético-barato, do kitsch, "destoando da 'prosa bem feita"' (SCHWARZ, 1999, p. 168). Enfim, a sugestão de uma prosa que ainda não amadureceu, com um veio talvez amadorístico, algo como uma "laranjada aguada-açucarada" (LINS, 1997, p. 12), mas acima de tudo com um colorido e uma pregnância própria que devem aparecer mais no todo do que na parte. É algo dessa ordem - aliás, algo que escapa da ordem - o desafio a que me referi: como deixar de lado um determinado padrão - também artificial (não é este o específico da arte?) do que é aceito como 'literário'?

Primeiramente reconhecendo que ele é de classe, é claro. Porque pobre não fala, sua palavra "é engolida a seco", "Massacrada no estômago com arroz e feijão" para que ele possa trabalhar "quetinho"3, palavra que é "defecada ao invés de falada". Só faremos justiça a essa prosa, portanto, se quebrarmos a barreira de classe que as formas acumuladas da tradição da prosa brasileira nos legaram, se soubermos escutá-la nas suas falhas, nas suas descontinuidades estruturais. Porque há certamente uma estruturação do livro que se dá pela "contínua descontinuidade" (PACHECO, 2007). É um dos poucos romances da literatura brasileira que abdicam da estruturação em capítulos ${ }^{4}$, para se construir em "segmentos breves, por vezes brevíssimos, separados em geral por um espaço em branco. De tal modo que a leitura faz-se por inúmeros cortes" (PACHECO, 2007, p.38). No vocabulário adorniano, poderíamos, entretanto, dizer que "a organização do livro responde a exigências do material: não há enredo que possa ser contado

3 Lembremos o "Todo mundo quetinho!", de Marreco, e entendamos o momento do crime como uma reversão momentânea e excepcional da divisão social do trabalho e sua ordem correspondente.

4 Um exemplo bem interessante na tradição brasileira é o Angústia, de Graciliano Ramos. Romance também pautado pelo ressentimento e pelo crime, mas que trabalha nos antípodas de Cidade de Deus, pois no mais arraigado plano individual, na mais estreita concisão, na tentativa de extirpar a musicalidade da linguagem, numa depuração que é quase essencialista e, sobretudo, na ausência sufocante de movimento, de atos que se externalizem. 
linearmente (os caminhos são labirínticos e imbricam-se), tampouco uma biografia que dê consistência ao romance (todas as vidas ali duram muito pouco)" (Idem). Se o Bildungsroman pautava-se justamente pela formação do herói individual burguês, o romance aqui deve dar conta da "formação" de toda uma geração de meninos cujo horizonte formativo é radicalmente outro. De certa maneira apreendemos o "sentido da vida" (LUKÁCS, 2000; BENJAMIN, 1985, p. 212) de cada um desses personagens juvenis, além de outros mais ${ }^{5}$. É justamente essa concentração da vida num momento definitivo que define o caráter do romance na reminiscência, assegura ao leitor a participação na morte da personagem e, portanto, o sentido mesmo daquela vida. O que acontece, entretanto, é que essa experiência limite da morte, morte definidora do sentido da vida, parece multiplicar-se exponencialmente tanto quanto diminui a duração da vida e seu sentido. A forma do romance, que tradicionalmente narrava o sentido da vida de uma personagem, passa aqui a narrar múltiplas e sucessivas vidas - permeadas ou culminando em múltiplas e sucessivas mortes -, cada vez mais sem sentido. Ao extrapolar a sua rica estrutura individual ou individualizante, a forma do romance explode aqui em multiplicidade sucessiva de vidas e mortes - cuja experiência cabe definir - que não mais aquecem a "vida gelada" do leitor (BENJAMIN, 1985, p. 214) e no limite até podem insensibilizá-lo - numa identificação com o destino alheio. E essas vidas que se queimam, que se consomem no limite do monstruoso e do banal, desde o início confrontadas com a morte, promovem a volta do elemento propriamente pedagógico da narrativa, numa descrição nada exemplar. Uma hipótese inicial é a de que não se trata de poesia épica, mas de uma espécie de epopeia negativa, no sentido de que não se trata aqui do início de um povo, mas de sua dissolução mesma, sua curva final.

Talvez pudéssemos compreender melhor as razões gritantes dessa estrutura de estilhaços se nos debruçarmos um pouco mais sobre as duas primeiras aberturas de página do romance.

A cena inicial do livro ganha no texto de Roberto Schwarz uma paráfrase exemplar:

No parágrafo de abertura, que é sutil, encontramos as pautas clássicas da vida popular brasileira, em toda a sua graça. Enquanto divide o baseado com um amigo, Barbantinho sonha com o futuro. Quer ser um salva-vidas com bom preparo físico. Não um desses relaxados, que por falta de exercício deixam o mar levar as pessoas. Até mesmo depois do expediente o menino cuidaria da forma, aproveitando o percurso entre a praia e sua casa para correr. "O certo era malhar sempre, alimentar-se bem, nadar o máximo possível." Em boa paz e sem susto para a consciência, o pé na irregularidade convive com a disposição prestativa, a ambição modesta, o respeito aos conselhos de quem sabe, o horário de trabalho, a atualização com o figurino em matéria de saúde, além da proteção de Iemanjá. Acresce que o pai e o irmão de Barbantinho também são salva-vidas, de modo que o menino está seguindo o bom exemplo. (SCHWARZ, 1999, pp. 163-4)

5 Lembremos o parágrafo anterior à morte do policial Cabeção, quando, num surto de fluxo de consciência concentrado, o narrador desfecha-lhe os tiros mortais, que, no entanto, são absolutamente irrelevantes do ponto de vista de uma justiça, seja ela poética ou metafísica. 
Para Schwarz, "essa constelação cordata e otimista", que tende a ser esfacelada pelo pesadelo que se vai armar, marca uma diferença que é constantemente reposta, estruturando uma "perspectiva histórica". Como para se contrapor à ruína das infâncias cooptadas pela guerra, o narrador faz surgir imagens e sons de infâncias que mesmo na sua pobreza merecem ser lembradas. Trata-se de um recurso essencialmente não conformista, que faz com que a narrativa do que é nunca elimine de uma vez por todas a narrativa do que poderia ser.

"Segundos depois de terem saído daquele casarão mal-assombrado, Barbantinho e Busca-Pé fumavam um baseado à beira do rio, na altura do bosque de Eucaliptos. Completamente calados, entreolhavam-se apenas quando um passava a bagana para o outro" (LINS, 1997, p. 11). São estas as palavras de abertura do romance. "Segundos" é a primeira palavra, crucial como sugestão dessa importante medida de tempo para o andamento das ações decisivas. Há uma rápida indicação de um lugar onde haviam estado - o casarão mal-assombrado - para descrever a ação presente. $\mathrm{O}$ passado acaba de ser presente, e este é circunstanciado por aquele. Eles estão parados e calados, mas a sugestão de uma rápida movimentação introduz e como que se inscreve na sua paz presente. Os personagens se encontram mergulhados na contemplação do exterior e na meditação de sua própria condição. O silêncio traduz a introspecção de ambos, imersos em elucubrações que correm, entretanto, em direções opostas: enquanto Barbantinho "sonha com o futuro", para ele garantido por um corpo forte que consiga dominar as águas, Busca-Pé se perde na arrebentação, num vai e vem entre passado e presente que não consegue vislumbrar um futuro certo. Em Barbantinho domina um sentimento de pertencimento: não somente em relação à família - ele seguirá o exemplo do pai e do irmão mais velho, sem contradição - mas também em relação a um sentimento religioso - aqui sob a proteção e benevolência de Iemanjá, mais adiante ao tornar-se evangélico (LINS, 1997, p. 371). Já em Busca-Pé a nota dominante é a da raiva, do ressentimento em relação ao que lhe foi reservado socialmente, dos obstáculos que se sobrepõem a seu desejo - desejo simples, e tratado como tal. O sentimento do primeiro, posto que positivo, não engendra a narrativa, mas lhe serve de contraponto e, em grande medida, no desenrolar das histórias, como saída - resignação religiosa. Já a raiva e o ressentimento, na sua negatividade mesma, são como o motor do trecho, aquilo que o faz consumir mais maconha, querer chutar o balde, querer passar ao crime... As imagens de mórbida opressão vêm como num turbilhão: os picos das montanhas são aniquilados pelas nuvens, o goiabal decepado, as praças tomadas por casas, os pés de jamelão, a figueira mal-assombrada e as mamoneiras assassinados, as alegrias pueris que morreram uma a uma, tudo antecedido pelos "prédios da Barra da Tijuca" que, "mesmo de longe, mostravam-se gigantescos" (LINS, 1997, pp. 11-2). Turbilhão do progresso, bem entendido, que a subjetividade vê aniquilando as montanhas, enquanto os modernos prédios se mostram. Essa desilusão em relação ao progresso move BuscaPé em direção ao tempo perdido, o que logo se converte em rememoração das ilusões perdidas: a ilusão de que sua vida era boa, das falsas promessas do estudo, da possibilidade do emprego digno. Tudo somado, desilusão em cima de desilusão, às 
quais o menino opõe seu desejo, desejo profissional, de realização: tornar-se fotógrafo ${ }^{6}$. A fala de sua mãe, irrompendo subitamente, tem o peso da História:

- Esse negócio de fotografia é pra quem já tem dinheiro! Você tem é que entrar para a Aeronáutica... Marinha, até mesmo pro Exército, pra ter um futuro garantido. Militar é que tá com dinheiro! Não sei o que você tem na cabeça não!

Uma das coisas mais curiosas de Cidade de Deus é trabalhar rigorosamente com o momento histórico da Ditadura Militar sem nunca dizê-lo abertamente. O marco inicial para os ações do romance são as enchentes de 1966, uma das piores da história do Rio de Janeiro. Sabemos dela como a causa da alocação de uma grande massa de desabrigados para os conjuntos habitacionais, cujas fundações se deram às pressas. $\mathrm{O}$ interessante é que em momento algum o romance vai mencionar essa data, e, pensando bem, datas não parecem ser o forte do romance. A impressão que fica é a de que a narrativa de alguma forma tenta se desvincular desses marcos históricos tão obrigatórios que são as datas, atendo-se a outros elementos para denotar historicidade - entre eles a emergente música de massa, numa exploração possível. Cidade de Deus é um estudo detalhado desse momento histórico, através de um ângulo praticamente inédito. Pois o imaginário que se cultiva da Ditadura Militar é em grande medida um imaginário de classe média, que se desdobra num apanhado de perseguições, torturas, exílios... (Não é preciso lembrar - mas não custa - que com isso eu não estou dizendo que essas práticas foram exclusivamente voltadas para a classe média, ou mesmo prioritariamente a ela, e muito menos que sejam apenas imaginárias, irreais ou fantasiosas. Mas o curioso aqui é notar que a figura do militar - que de resto pouco aparece nas notas narrativas, com exceção da polícia militar - surge aqui na consciência de um personagem que aspira à classe média, partilhando certo horizonte desta). Aqui, tudo se passa como se a História Brasileira que foi abortada em 1964, dividindo-se no antes e no depois da historiografia, não tivesse se dado. O corte que existe em seu lugar é o ocasionado pelo advento das enchentes. Apesar da criação do conjunto habitacional datar de antes do golpe de 64 assim como a política de remoção de favelas - a narrativa se monta através da vinda das vítimas sobreviventes dessa catástrofe urbana. A catástrofe político-social é transmutada em catástrofe natural. Esta é da esfera do imponderável, do inevitável, que a esfera da política, por sua vez, tendeu tradicionalmente a se opor, uma vez que a sua especificidade é trabalhar no campo da plausibilidade. No entanto, é o próprio romance que vai mostrar que a catástrofe natural foi produto de uma política social específica, de expulsão e segregação social forçada (expulsão e segregação elevadas à potência em caso de homossexualismo):

6 Sabemos que a aproximação que o narrador faz aqui de Busca-Pé, no filme Cidade de Deus torna-se identidade. O filme, ao torná-lo a matriz do foco narrativo, seu narrador mesmo, aponta idealmente para uma solução, para uma saída que é, na melhor das hipóteses, individual - portanto falsa. Como se não fosse o bastante, essa saída se dá através da espetacularização da barbárie e da violência - que ele flagra com sua câmera, aproveitando-se do fato de pertencer aos "dois mundos". Resultado: é impossível escapar desse mundo de violência, mas é possível assumir uma postura cínica na qual o importante é saber se aproveitar dele - o que não foi muito diferente do que o próprio filme fez. 
Cabeleira nada falou. Alguma coisa o fez lembrar-se de sua família: o pai, aquele merda, vivia embriagado nas ladeiras do morro do São Carlos; a mãe era puta da zona e o irmão, viado. A mãe piranha até que passava, era conhecida por sua personalidade forte, não levava desaforo pra casa, tinha palavra e era respeitada no Estácio. O pai também não era o seu maior problema, porque, quando sóbrio, as crianças não riscavam seu rosto de giz, não lhe roubavam os sapatos, e, apesar disso tudo, ele era bom de briga e ritmista de escola de samba. Mas o irmão... era muita sacanagem... Ter um irmão viado foi uma grande desgraça em sua vida. Imaginava o Ari chupando o pau dos Paraíbas lá na Zona do Baixo Meretrício, dando o cu para a garotada do São Carlos, fazendo troca-troca com marinheiros e gringos na praça Mauá, comendo bunda de bacana nos pulgueiros da Lapa. Não aceitava que seu irmão passasse batom, vestisse roupas de mulher, usasse perucas e sapatos de saltos altos. Lembrou-se também daquela safadeza do incêndio, quando aqueles homens chegaram com saco de estopa ensopado de querosene botando fogo nos barracos, dando tiro para todos os lados sem quê nem porquê. Fora nesse dia que sua vovó rezadeira, a velha Benedita, morrera queimada. Já não podia sair da cama por causa daquela doença que a obrigara a viver deitada. "Se eu não fosse molequinho ainda", pensava Cabeleira, "eu tirava ela lá de dentro a tempo e, quem sabe, ela tava aqui comigo hoje, quem sabe eu era otário de marmita e o caralho, mas ela não tá, morou? Tô aí pra matar e morrer". Um dia após o incêndio, Cabeleira foi levado para casa da patroa de sua tia. Tia Carmem trabalhava no mesmo emprego havia anos. Cabeleira ficou morando com a irmã da mãe até o pai construir outro barraco no morro. Ficava entre o tanque e a pia o tempo todo e foi dali que viu, pela porta entreaberta, o homem do televisor dizer que o incêndio fora acidental. Sentiu vontade de matar toda aquela gente branca, que tinha telefone, carro, geladeira, comia boa comida, não morava em barraco sem água e sem privada. Além disso, nenhum dos homens daquela casa tinha cara de viado como o Ari. Pensou em levar tudo da brancalhada, até o televisor mentiroso e o liquidificador colorido. (LINS, 1997, pp.25-6)

Uma política social não nomeada, mas sugerida pelas narrativas, que não mostra rupturas - antes continuidade, continuidade da segregação - entre o antes e o depois da ditadura, a ponto de prescindir assim do próprio significante ditadura. $\mathrm{O}$ trecho é também exemplar como descrição ultraconcisa da 'formação' da personagemchave da primeira parte do romance, o próprio Cabeleira, descrição que vai do discurso direto ao discurso indireto livre para traçar tanto o círculo edípico quanto o círculo de impotência face ao desejo do outro e à exclusão social, estes nada simplistas e não mutuamente excludentes, como se vê. Nota narrativa cujo mergulho psicológico é notável pela objetividade com que diz o essencial da personagem, no qual o imaginário obsceno - carregado pelas pretensas práticas sexuais do irmão - se mistura a momentos decisivos de sua vida - como o do homem do televisor - num nó subjetivo que o constitui. Não custa frisar que este poder de condensação demonstra não apenas conhecimento profundo da matéria, mas grande talento literário: as imagens e os pensamentos da personagem se desdobram com incrível naturalidade, tudo garantido por técnicas literárias já há muito estabelecidas, porém ainda assim eficazes. Multiplicar esse procedimento, como o romance o faz, pressupõe não apenas um radical mergulho 
nessa matéria social, mas a capacidade de ser fiel a ela, aderindo às questões que lhe são próprias.

O passado para o narrador é o passado das personagens que narra, que são muitas, condensadas nas muitas narrativas. Poderíamos resumir a de Busca-Pé da seguinte maneira: as esperanças de cidadania plena - não ter de passar fome quando a comida é abundante, ter direito à instrução e ao trabalho minimamente digno - só fizeram sentido até 1964, para então ser substituído por um mundo forçosamente cindido, cisão essa da qual Cidade de Deus - o conjunto habitacional - é parte e testemunha. Não é, entretanto, isso que o narrador apreende na consciência da personagem: aqui o destino execrável imposto aos pobres aparece como que dado num continuum temporal sem diferença, quase que como um destino, cujo único contraponto é a infância harmonizada com a natureza ${ }^{7}$. Mas as marcas da história estão lá: a fala da mãe tem o peso da realidade, na qual o Capital e o militarismo golpista se aliam para impedir que esse destino execrável seja posto em dúvida. Restaria então somente se aliar ao inimigo, virar milico - ideia que só faz aumentar a raiva da personagem. Fumar muita maconha é a única maneira que ele vê de apaziguar a raiva, um problema se a própria erva é ilegal e serve de álibi para os excessos da repressão militar. Entre o mundo dos maconheiros e o mundo oficial se esboça uma oposição, algo como a (já mais do que tradicional) contraposição de liberação versus repressão - oposição mais ou menos incentivada pela música americana e por parte significativa da nossa canção mais avançada (“Tim Maia, Caetano, Gil, Jorge Ben, Big-Boy”) (LINS, 1997. p.13). Mas tanto a liberação quanto a repressão aparecem como figuras em combate na consciência amaconhada de Busca-Pé, que acompanhamos. Nessa luta interna, luta que se debate na iniquidade, percebemos como a desejada máquina fotográfica se apresenta para ele como a arma de fogo se apresentará para tantos outros - até para ele mesmo -, como possibilidade de vida, de reconhecimento social. O que o aguardava do outro lado? A aula de datilografia, a escola, o esforço sem fim nem garantia, ou o destino como corpo coberto das novas insígnias do reconhecimento social - "trajando calça Lee, tênis Adidas" (LINS, 1997, p.14) -, mas ensanguentado e coberto pelas sanguessugas? A vida dos 'otários' trabalhadores - mais longa - ou a curta, mas intensa, vida do 'bichosolto'?

$\mathrm{Na}$ cronologia de fatos narrados, o trecho que abre o romance localiza-se no meio da guerra do tráfico. Ele começa in medias res, e só somos levados a desconfiar disso ao final desse começo:

Era a guerra que navegava em sua primeira premissa. A que se fez soberana de todas as horas vinha para levar qualquer um que marcasse bobeira, lançar chumbo quente em crânios párvulos, obrigar bala perdida a se achar em corpos inocentes e fazer Mané Galinha correr, com o diabo no seu coração batendo forte, pela rua lá da

7 O que faz lembrar Walter Benjamin: "A tradição dos oprimidos nos ensina que o estado de exceção em que vivemos é na verdade regra geral" (LÖWY, 2001, p. 67). Ou, nas palavras do narrador: "Resignava-se em seu silêncio com o fato de rico ir para Miami tirar onda, enquanto o pobre vai pra vala, pra cadeia, pra puta que pariu" (LINS, 1997, p.12). 
Frente, levando uma tocha de fogo nas mãos para incendiar a casa do assassino de seu irmão. (LINS, 1997, p.14)

O romance se pauta por uma estrita referencialidade espacial. O casarão malassombrado, a beira do rio, o bosque de Eucaliptos, são aqui, no segmento individual, apenas nomeados - assim como mais adiante serão o Lá em Cima, Lá na frente, Lá do outro lado do Rio... -, mas sua grande recorrência em diversos dos outros segmentos vai costurar uma espacialidade viva que, no limite, fará prescindir de qualquer descrição certamente algo que contribui para a lepidez do estilo em questão. O leitor é apresentado à guerra através de "passos obtusos" (LINS, idem), com a realidade da morte que surge boiando no rio. A explicação do narrador nos joga em plena guerra, confrontando-nos com uma personagem que ignoramos por completo. Temos como um lampejo de ação em meio a uma cena de estupefação - de dormência narcótica - na qual as personagens isoladas veem-se a si mesmas confrontando-se com o espaço. Há uma subjetividade que se pauta pelo espaço estático e pela duração, pela contemplação. Em oposição a essa subjetividade surge um mundo em movimento que rapidamente dissolve a relativa paz instaurada, pondo as personagens em movimento por sua vez. É importante, entretanto, notar como esses polos são reversíveis e não estanques em suas posições. A estupefação inicial das personagens é preenchida por movimento. $\mathrm{O}$ imperativo de Barbantinho é "Malhar sempre, alimentar-se bem, nadar o máximo possível" (LINS, 1997, p. 11). Em Busca-Pé, instala-se um conflito fundamental em relação a sua posição no mundo, que o impele a uma torrente de lembranças, de desabafos, de imagens. Tudo se dá como um eco do movimento subjetivo na quietude da contemplação. Mas as personagens são como que expulsas dessa duração estática por um corpo em movimento, corpo que não permite a ancoragem subjetiva como anteparo para o fluxo interno de consciência. Se em segundos Barbantinho e Busca-Pé saíram do casarão mal-assombrado para parar no bosque de Eucaliptos, com menos segurança, mas não tão rápido eles voltam para casa. A trajetória desse trecho inicial de Cidade de Deus vai do movimento livre, que escolhe o repouso, à movimentação imposta, que imobiliza no medo. Por outro lado, traça-se um movimento que vai do estado de plenitude - Barbantinho boiando todo poderoso entre o sagrado do céu e do mar - ao desespero suplicante:

Busca-Pé chegou em casa com medo do vento, da rua, da chuva, do seu skate, do mais simples objeto, tudo lhe parecia perigoso. Ajoelhou-se diante da cama, jogou a cabeça no colchão, as mãos sobre ela, e numa súplica infinita pediu a Exu que fosse lá avisar a Oxalá que um de seus filhos tinha a sensação de estar desesperado para sempre. (LINS, 1997, p. 15)

Outra dimensão que permeia essa abertura é a religiosa. Somos confrontados a pelo menos três modos religiosos: um protestante, um católico e um afro-brasileiro. O modo protestante é evidentemente o menos visível aqui, uma vez que a própria prática de fumar maconha tende a ser banida pela sua doxa estrita. Mas algo desse modo religioso vive na disposição permanente para o trabalho, na realização da vocação pelo 
trabalho, por parte de Barbantinho (de qualquer modo, lá pelo final da segunda parte do romance, ficamos sabendo por meio de Busca-Pé que Barbantinho "virou crente" e não fumava mais maconha). Já o modo católico aparece na tensa meditação de Busca-Pé, que ficamos sabendo se confessava quando mais novo ao padre Júlio. Por mais que a sua rebeldia o faça querer refazer todos os pecados confessados - o que demonstra não apenas a ausência de arrependimento, mas o próprio caráter de negociação do perdão católico - não há como dizer que Busca-Pé não fora bem "catequizado": tem escolaridade e não consegue passar para o mundo do crime, por mais que queira e tencione fazê-lo excepcionalmente. O modo afro-brasileiro virá ao final, no momento do desespero, como recurso e crença última e ao mesmo tempo fundamental. Ela já estava ali presente desde o começo, como insinuação de Iemanjá brincando imaginariamente no corpo de Barbantinho, sugerindo a pregnância das crenças e práticas afro-brasileiras na extensão do romance como um todo. Em Cidade de Deus, a vigência do politeísmo é geral e mesmo caracteriza até certo ponto a individuação operada pela narrativa, individuação muito mais ligada ao particular da divindade do que a algum tipo de subsunção ao universal da igualdade perante a Lei.

Semelhante perspectiva de uma justiça divina particular está expressa pela citação que abre o presente texto. A destruição de muitas favelas por conta da grande enchente de 1966 e a morte de 300 pessoas na de 1967 puderam ser vistas por determinadas classes no Brasil como uma superação mágico-religiosa para um problema essencialmente social - moradia - cuja solução é justamente aquilo que é evitado por se colocar o problema, ou melhor dizendo, a solução, em termos não sociais. É como se Deus tivesse posto abaixo o mundo já corrompido e decadente das favelas para reconstruir para aquele povo um lugar - a Cidade de Deus - sob os Seus auspícios: um delírio não muito distante das perspectivas postas em cena pelos militares no poder, como se viu. Contudo, percebemos como essa perspectiva mágico-religiosa-naturalista é até certo ponto partilhada pelo início da narrativa de Paulo Lins, mas em sentido inverso: a desgraça natural que vem como castigo converte-se numa dádiva natural com direito a halo encantado - para aquelas crianças cujo futuro em parte se tratará de narrar (justamente na segunda abertura de página). Ao mesmo tempo em que as classes dominante e média não escapam ao universo da superstição, também a narrativa não escapa de todo do mundo de suas formas e concepções. $\mathrm{O}$ sentido do emprego dessas formas, assim como o de sua utilização com mais ou menos propriedade, vai, entretanto, variar em cada caso. Assim como seus resultados. 


\section{Referências bibliográficas}

BENJAMIN, Walter. Magia e técnica, arte e política. São Paulo: Brasiliense, 1985.

DEL LUNGO, Andréa. L'incipit Romanesque. Paris: Le Seuil, 2003.

DUBOIS, Jean. Dicionário de linguística. São Paulo: Pensamento Cultrix, 2004

LINS, Paulo. Cidade de Deus. São Paulo: Companhia das Letras, 2007.

LÖWY, Michel. Walter Benjamin: Avertissement d'incendie. Paris: PUF, 2001.

LUKÁCS, Georg. Teoria do Romance. São Paulo: Duas Cidades/34, 2000.

MICHEL, Natacha. L'écrivain Pensif. Paris: Verdier, 1998.

PACHECO, Ana Paula. “Cidade-Cárcere”. In: Terceira Margem. v. 16, 2007, pp. 2745.

PASTA JR., José Antônio. “O Romance de Rosa: Temas do Grande Sertão e do Brasil". Novos Estudos CEBRAP, ed. 55, 1999, pp.61-70.

SCHWARZ, Roberto. Sequências Brasileiras. São Paulo: Companhia das Letras, 1999. 